\title{
Selection of the surgical approach for lesions with parapharyngeal space involvement: A single-center experience on 153 cases
}

\author{
Davide Lombardi $^{\mathrm{a}, *}$, Marco Ferrari ${ }^{\mathrm{a}, \mathrm{b}}$, Alberto Paderno ${ }^{\mathrm{a}}$, Stefano Taboni ${ }^{\mathrm{a}}$, Vittorio Rampinelli ${ }^{\mathrm{a}}$, \\ Francesco Barbara $^{\mathrm{c}}$, Alberto Schreiber ${ }^{\mathrm{a}}$, Davide Mattavelli ${ }^{\mathrm{a}}$, Michele Tomasoni ${ }^{\mathrm{a}}$, Davide Farina ${ }^{\mathrm{d}}$, \\ Marco Ravanelli ${ }^{\mathrm{d}}$, Roberto Maroldi ${ }^{\mathrm{d}}$, Piero Nicolai ${ }^{\mathrm{b}}$ \\ ${ }^{a}$ Unit of Otorhinolaryngology - Head and Neck Surgery, Department of Medical and Surgical Specialties, Radiologic Sciences, and Public Health, University of Brescia, \\ Brescia, Italy \\ ${ }^{\mathrm{b}}$ Section of Otorhinolaryngology - Head and Neck Surgery, Department of Neurosciences, University of Padua, Padua, Italy \\ ' Unit of Otolaryngology and Head and Neck, P.O. "Mons. R. Dimiccoli", Barletta, Italy \\ ${ }^{\mathrm{d}}$ Unit of Radiology, Department of Medical and Surgical Specialties, Radiologic Sciences, and Public Health, University of Brescia, Brescia, Italy
}

\section{A R T I C L E I N F O}

\section{Keywords:}

Parapharyngeal imaging

Parapharyngeal neoplasm

Parapharyngeal space

Surgical approach

\begin{abstract}
A B S T R A C T
Background: The parapharyngeal space (PPS) can harbor a variety of tumors that can be approached through a wide spectrum of surgical routes. A decisional algorithm on the surgical approach to resect PPS lesions was tested in terms of reliability by retrospectively applying it to a large series of patients.

Methods: Patients treated at the Unit of Otorhinolaryngology - Head and Neck Surgery of the University of Brescia, Italy, for tumor or tumor-like lesions involving the PPS between October 1986 and July 2019 were included in the retrospective analysis. Tumor characteristics, clinical presentation, diagnostic work-up, type of resection, surgical approach, and oncologic and morbidity outcomes were reviewed. Reliability of the algorithm was calculated as the number of cases in which the expected approach was confirmed/total number of cases $\times 100$.

Results: The analysis included 153 patients. Most lesions (64.1\%) were benign. The most frequent complaint at presentation was unilateral oropharyngeal medialization (47.1\%), followed by neck/parotid swelling (41.2\%). Ninety-two (61.3\%) lesions were excised through an enucleation/extracapsular dissection. Wide-margin resection and compartmental resection were performed in $17(11.3 \%)$ and 41 (27.3\%) patients, respectively. A singlecorridor approach was employed in 132 (87.4\%) cases. Combinations of multiple corridors were adopted in 19 (12.6\%) patients. Reliability of the decision-making algorithm was $91.2 \%$. Capsular integrity and margin status affected prognosis of pleomorphic adenomas and PPS malignancies, respectively.

Conclusion: The proposed decision-making algorithm can reliably guide approach selection, which should primarily aim at ensuring intact-capsule excision of benign lesions suspicious for pleomorphic adenomas and clearmargins resection of PPS malignancies.
\end{abstract}

\section{Introduction}

The parapharyngeal space (PPS) is a fascial space of the neck surrounded by a number of regions and structures that have major relevance for head and neck surgeons $[1,2]$. As a consequence of its intricate location and variety of tumors that it can harbor, the PPS has historically raised particular interest among head and neck surgeons.

The rarity and prevalent benign nature of PPS tumors pose a challenge since surgical excision may have a significant impact on the patient's quality of life $[3,4]$. Consequently, a "wait and scan" policy in selected asymptomatic, benign PPS tumors should also be considered [5].

When surgery is indicated, thorough knowledge of the wide spectrum of approaches is required to adequately resect the tumor while minimizing morbidity. It is generally accepted that transcervical/ transcervical-transparotid approaches are the workhorse in the surgical management of PPS tumors. However, the increasing availability of new surgical routes and technologies has provided surgeons with a

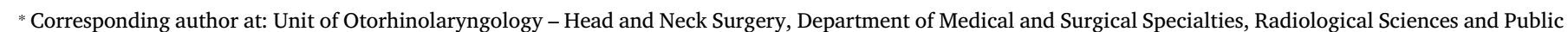
Health, University of Brescia, Piazzale Spedali Civili 1, 25123 Brescia, Italy.

E-mail address: davinter@libero.it (D. Lombardi). 
wider range of options, whose indications and limits still need to be fully elucidated [6-9].

Based on a previous anatomical study, we developed a decisional algorithm on the surgical approach to resect PPS lesions, [10] which was lacking clinical validation. Therefore, we tested the reliability of this algorithm by retrospectively applying it to a series of 153 patients treated at a single tertiary care center. The principal aim of the paper is to provide thorough insight on several issues that may help in selecting the ideal surgical approach among the currently available options.

\section{Materials and Methods}

A database on patients treated at the Unit of Otorhinolaryngology Head and Neck Surgery of the University of Brescia, Italy, for tumor or tumor-like lesions involving the PPS between October 1986 and July 2019 was retrospectively reviewed. Both the prestyloid (otherwise referred to as "true PPS") and retrostyloid (also defined as "carotid space") compartments were intended as parts of the PPS, [3,4] which was defined as the space bounded by the skull base cranially, buccopharyngeal fascia medially, prevertebral fascia posteriorly, stylomandibular tunnel and nodal level IB and IIA laterally, interpterygoid fascia anteriorly, and the axial plane passing through the posterior end of the greater horn of the hyoid inferiorly [1,2,10-15].

\section{Tumor characteristics}

Tumors were classified in terms of behavior (benign $v s$. malignant), presentation (primary vs. recurrent), and type of PPS involvement, which was defined as primary if the mass arose within the PPS, or secondary when the lesion developed from a neighboring compartment. The origin of the tumor (i.e. anatomic structure from which the lesion originated) was also assessed. Extension of the tumor within the PPS was described as rate of involvement of 5 subunits (upper prestyloid, upper retrostyloid, middle prestyloid, middle retrostyloid, lower PPS), according to Prasad et al. $[10,16]$. Degree of vascularization and critical relationship with major neurovascular structures and adjacent regions were also analyzed.

Tumor histology was defined according to the latest version of the World Health Organization Classification of Head and Neck Tumours [17].

\section{Clinical presentation and diagnosis}

Symptoms and signs at the time of referral were described in terms of rate at presentation. Associations of complaints with tumor behavior were tested with a Chi-square test or Fisher's exact test, as appropriate.

Rates of patients who underwent preoperative contrast-enhanced computed tomography (CECT), magnetic resonance imaging (MRI), transarterial angiography with temporary balloon occlusion (TBO) test of the internal carotid artery (ICA), ultrasound-guided fine-needle aspiration cytology (FNAC), or incisional or thru-cut biopsy were calculated. Diagnostic accuracy of different preoperative work-up schedules was calculated; diagnosis was considered as correct when both the behavior of the disease (benign $v s$. malignant) and category of the mass (salivary, neurogenic, mesenchymal, vascular, nodal, congenital, pharyngeal-epithelial) were reliably predicted.

\section{Types of resection and surgical approaches}

Types of resection were classified as follows Figure 1:

- Enucleation consisted of removal of the mass without any margin of normal tissue; it was considered adequate for non-recurrent, benign PPS lesions (e.g. pleomorphic adenomas [PA], schwannomas, paragangliomas, branchial cysts, lipomas, Warthin's tumor). Intracapsular debulking with subsequent resection were performed for selected neurogenic lesions and were considered as variants of enucleation [18]. For PAs, areas of contiguity between the tumor and parotid gland were dissected following the principle of extracapsular dissection, thus leaving, whenever possible, a thin cuff of normal tissue instead of bluntly dissecting the surface of the lesion $[19,20]$.

- Wide margin resection was defined as resection of the mass surrounded by either a $1-\mathrm{cm}$ margin of normal tissue or by an uninvolved anatomical barrier such as a thick bony or muscular structure; it was considered adequate for non-recurrent, low-grade PPS malignancies or nodal metastases from a poorly-aggressive primary (e.g. well-differentiated thyroid cancer).

- Compartmental resection consisted of the clearance of the PPS, potentially extended to adjacent compartments, major vessels, and/or named nerves based on tumor extension. It was indicated whenever one or more of the following characteristics was present: multinodular recurrence, nodal metastases from aggressive primary lesions (e.g. salivary tumors), macroscopic perineural invasion, highgrade PPS malignancies.

Each surgical approach was classified as lateral (when passing through the lateral neck, parotid space, mandibular body/ramus, and/ or lateral skull base), medial (when passing through the sinonasal tract, oral-oropharyngeal cavity, with or without anterior mandibulotomy), or combined (when a lateral and a medial - type 1 combination - or two medial - type 2 combination - or a lateral and two medial approaches type 3 combination - were used simultaneously).

A sub-analysis was performed on patients in whom combined approaches were used, focusing on rates of malignancy, recurrent tumors, and primary $v s$. secondary PPS involvement.

\section{Approach selection}

Preoperative imaging was reviewed (MF, ST, DF, MR, RM) to contour the boundary of the tumor and establish the volume to be resected in keeping with the aforementioned criteria. Based on our previous anatomical study, [10] a simplified version of our original algorithm to guide selection of the approach was retrospectively applied to all cases in a blinded fashion with respect to the actual approach employed. Criteria to select the approach are summarized in Figures $2-4$. Reliability of the algorithm was calculated as the number of cases in which the expected approach was confirmed/total number of cases $\times 100$.

\section{Margin status, adjuvant treatment, and disease control}

Margins were classified as uninvolved or involved based on definitive pathological examination. The rate of patients undergoing adjuvant radiation therapy (RT) was calculated. Disease control was evaluated as locoregional control (LRC) through Kaplan-Meier analysis. Margin status, rate of adjuvant RT, and LRC were evaluated for the following histologies: PA, paraganglioma, schwannoma, and malignancies of the PPS. The log-rank test was adopted to analyze the following factors: in primary PAs, intraoperative capsular rupture and margin status; in recurrent PAs, margin status and adjuvant RT; in PPS malignancies, tumor origin and margin status.

\section{Treatment-related morbidity}

Length of hospitalization, rate of temporary tracheostomy, and complications were tested for association with type of approach (uniportal vs. combined) through Kruskal-Wallis test, Chi-square, and Fisher's exact, as appropriate. Severity of postoperative complications was classified according to Clavien-Dindo [21].

For all statistical tests, the level of significance was set at 0.05 . Pvalues between 0.05 and 0.10 were defined as close-to-significant. 

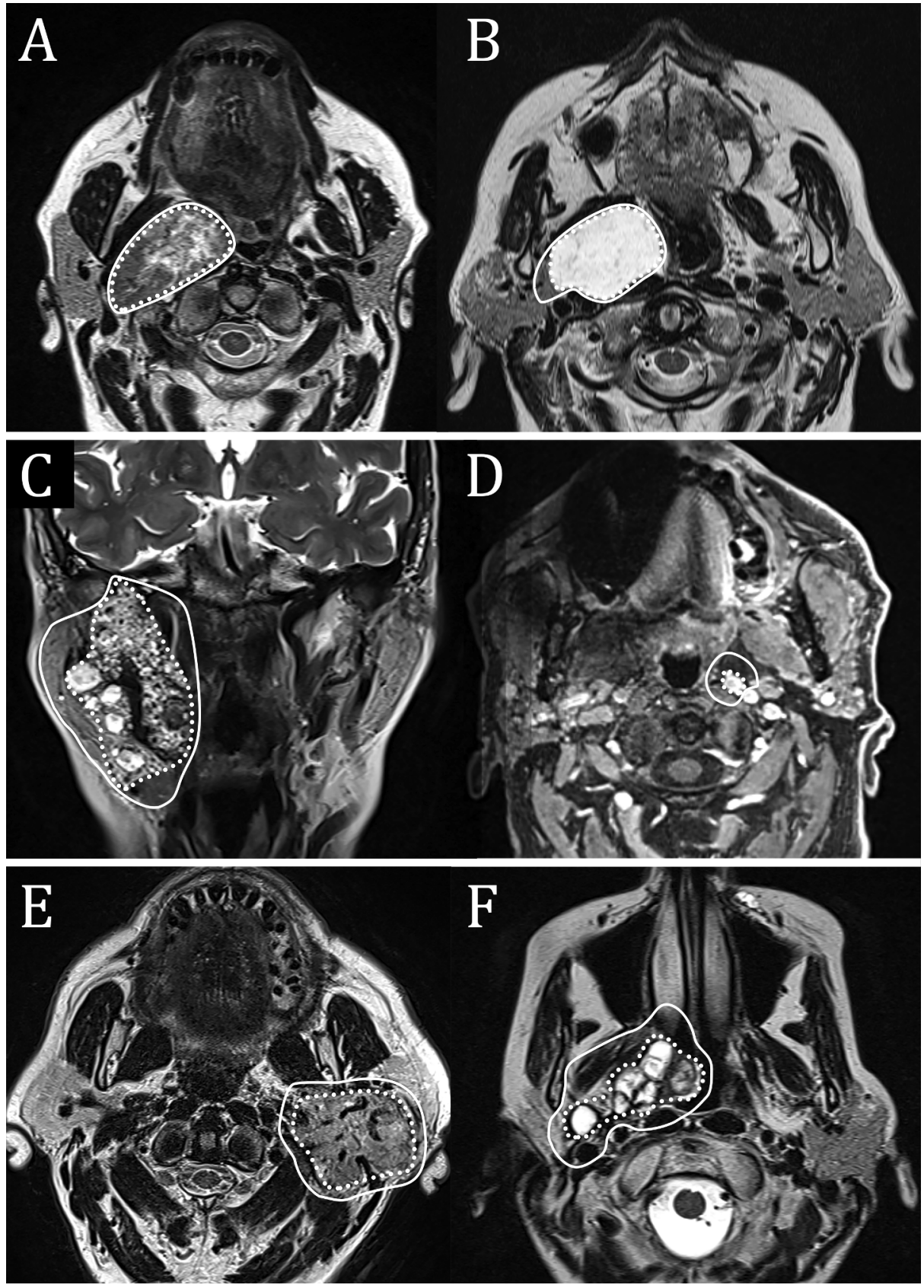

Figure 1. Panel exemplifying different types of resections, depending upon histology of the tumor. Dotted lines show the macroscopic boundary of the tumor, continuous lines mark the planned resection. A. Schwannoma of the right sympathetic trunk, which was deemed resectable through simple enucleation following microdebrider-aided intracapsular debulking. B. Pleomorphic adenoma of the right parapharyngeal space displaying an area of contact with the deep portion of the parotid gland. The planned resection included a thin cuff of normal parotid parenchyma adjacent to the tumor (i.e. extracapsular dissection technique). C. Multinodular, recurrent pleomorphic adenoma of the right parotid gland with parapharyngeal space involvement. In view of the multifocal appearance of the tumor, a compartmental resection of the entire parapharyngeal, parotid, and submandibular space was planned. D. Single-node, retropharyngeal left nodal recurrence of a sinonasal undifferentiated carcinoma. The planned resection included the enhancing nodal tissue along with a 1-cm layer of normal surrounding tissue, wherever achievable (i.e. wide margin resection). E. Left parotid metastasis of clear cell renal carcinoma with parapharyngeal space involvement in an otherwise disease-free patient. Metastasectomy was performed with $1 \mathrm{~cm}$ of normal surrounding tissue (i.e. wide margin resection). F. Multinodular, recurrent chondrosarcoma of the right parapharyngeal space, which was managed through compartmental resection given the well-known local aggressiveness of the tumor.

\section{Results}

One hundred fifty-three patients matched the inclusion criteria. The number of patients treated for PPS tumors or tumor-like lesions increased over time, from 4 cases in the 1980s to 49 cases between 2015 and 2019 (Supplementary Figure 1).

\section{Tumor characteristics}

Main tumor characteristics are summarized in Table 1. Most lesions were benign (98/153, 64.1\%), non-recurrent (109/153, 71.2\%), and primary $(140 / 153,91.5 \%)$. Distribution of histological diagnoses of tumors included in the series is reported in Table 2. Additional characteristics and local extension of tumors are summarized in Supplementary Tables 1 and 2.
Clinical presentation and diagnosis

The most frequent complaint at presentation was unilateral oropharyngeal medialization (72 patients, $47.1 \%$ ), followed by neck/ parotid swelling (63 patients, $41.2 \%$ ), in addition to other findings summarized in Supplementary Table 3. Neck/lateral facial numbness was significantly associated with malignancy $(80.0 \%$ vs. $25.0 \%$, $\mathrm{p}=0.0002$ ). No other significant associations between clinical presentation and malignancy were found.

All patients were preoperatively studied with at least a cross-sectional imaging modality (CECT, MRI, or both); CECT was performed in $40(26.1 \%)$ patients, MRI in 135 (88.2\%), and transarterial angiography with TBO test of ICA in 9 (5.9\%). Preoperative diagnostic work-up consisted of imaging alone in $70(45.8 \%)$ patients, imaging and FNAC in $59(38.6 \%)$, and imaging and biopsy (either thru-cut or incisional) in $24(15.7 \%)$. Diagnostic accuracy was estimated as $90.0 \%, 77.3 \%$, and $87.5 \%$, respectively. 


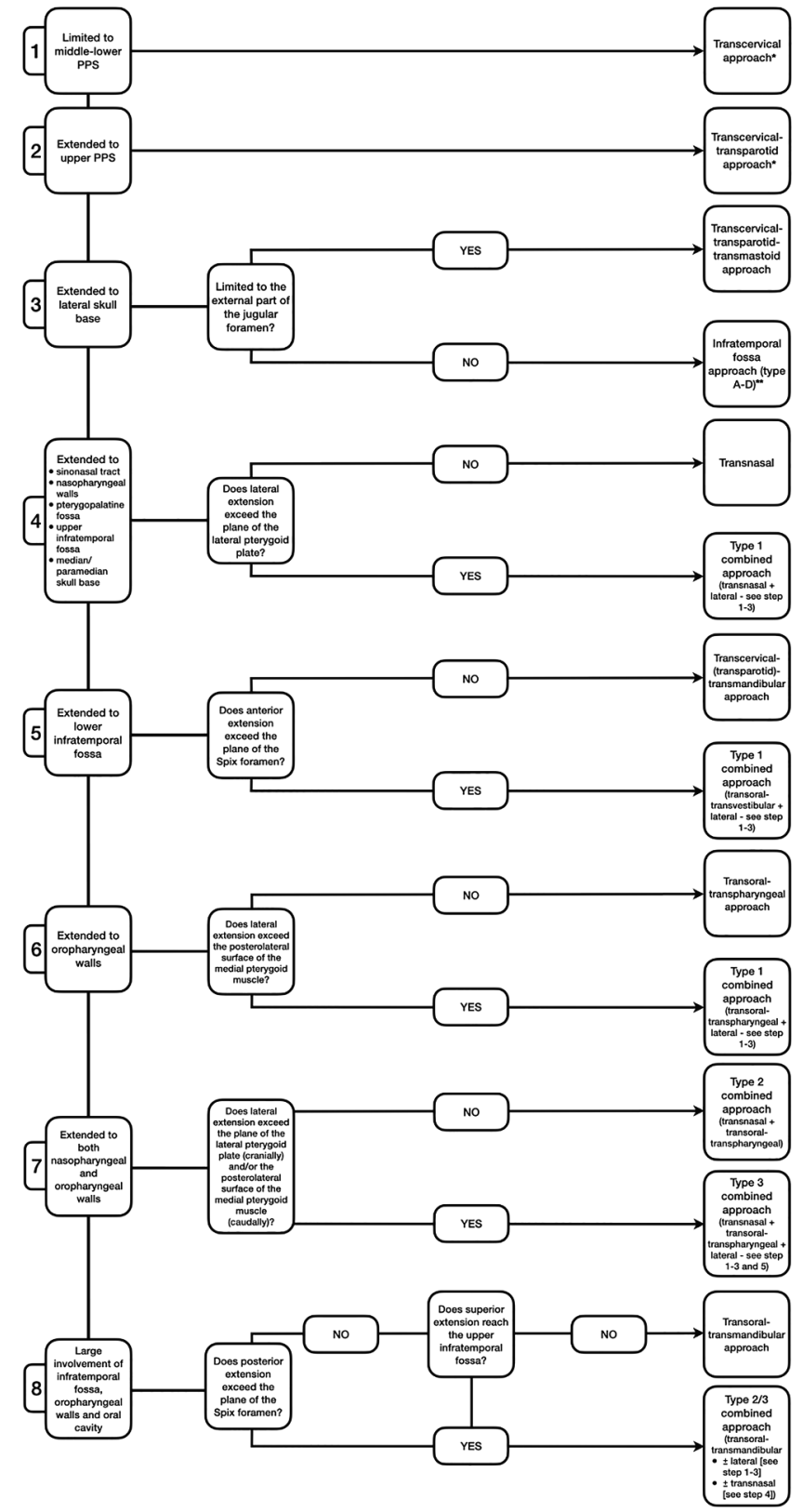

Figure 2. Eight-item checklist summarizing the algorithm for selection of the surgical approach based on planned resection. Of note, "extension" refers to extension of the planned resection, and not to radiologically appreciable tumor extension. *Of note, decision on whether or not a parotidectomy is required also depends upon the relationship of the lesion with respect to the deep portion of the parotid gland, an issue that needs to be addressed preoperatively and confirmed intraoperatively. Tumors arising from the deep portion of the parotid gland, indeed, require at least partial parotidectomy, regardless of extension towards the upper parapharyngeal space, to minimize the risk of unintended damage to the facial nerve; lesions resulting easily cleavable from the parotid, conversely, may require parotidectomy only for exposure purposes. **Specific indications of the type of infratemporal approach are in line with Prasad et al.[16]

\section{Types of resection and surgical approaches}

Data on the type of resection and surgical approach were available in 150 (98.0\%) and 151 (98.7\%) patients. Ninety-two (61.3\%) lesions were excised through an enucleation/extracapsular dissection, which was facilitated by endoscope-assisted microdebrider cavitation in 5 schwannomas [18]. Wide-margin resection and compartmental resection were performed in $17(11.3 \%)$ and 41 (27.3\%) patients,

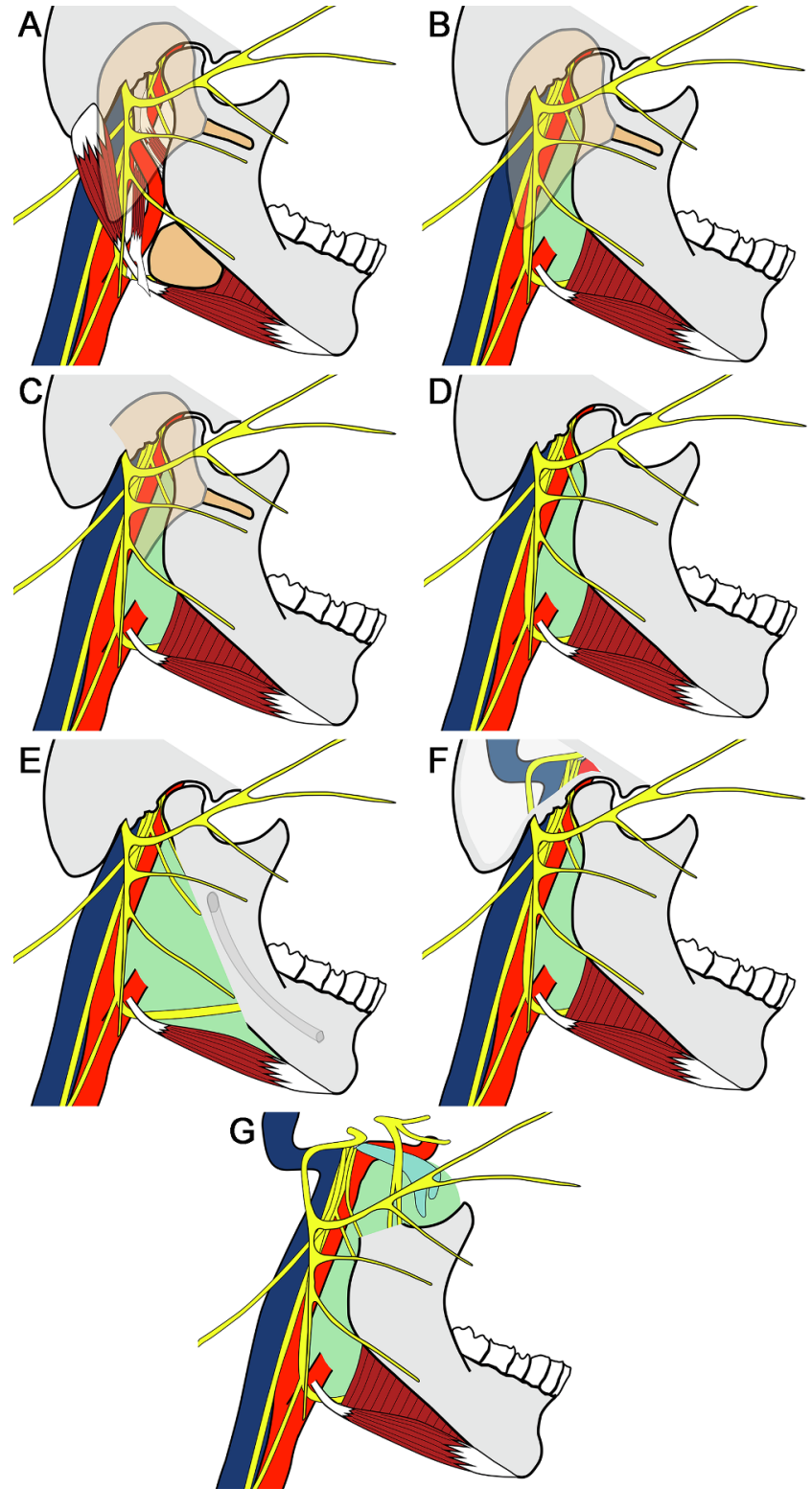

Figure 3. Scheme illustrating relevant surgical anatomy of lateral approaches. A. Overview of surgical anatomy of lateral approaches. B. Transcervical approach. C. Transcervical-transparotid approach with partial parotidectomy (modified technique). D. Standard transcervical-transparotid approach. E. Transcervicaltransmandibular approach. F. Transcervical-transparotid-transmastoid approach. G. Infratemporal fossa approach.

respectively.

A single-corridor approach was employed in 132 (87.4\%) cases. Combinations of multiple corridors were adopted in 19 (12.6\%) patients. Rates of employment of the different surgical approaches are summarized in Table 3.

Compared to patients treated with a uniportal approach, those receiving a combined approach had a significantly higher rate of malignancy $(68.4 \%$ vs. $30.3 \%, \mathrm{p}=0.001)$, higher rate of recurrent tumors (68.4\% vs. 19.7\%, p < 0.0001), and higher rate of secondary PPS involvement $(42.1 \%$ vs. $3.0 \%, \mathrm{p}<0.0001)$.

Approach selection

Reliability of the decision-making algorithm reported in Figure 1 was $91.2 \%$, which resulted in 135 of 147 approaches being correctly predicted ( 6 cases did not have enough information to be included in 



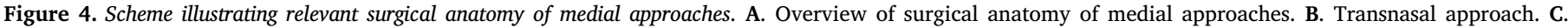
Transoral-transpharyngeal approach. D. Transoral-transvestibular approach. E. Transoral-transmandibular.

Table 1

Characteristics of tumors/tumor-like lesions.

\begin{tabular}{|c|c|}
\hline Variable & Distribution \\
\hline Gender & $\begin{array}{l}\text { Male: } 74 / 153(48.4 \%) \\
\text { Female: } 79 / 153(51.6 \%)\end{array}$ \\
\hline Age (years) & $\begin{array}{l}\text { Median: } 50 \\
\text { Overall range: } 5-85 \\
\text { Interquartile range: } 38-62\end{array}$ \\
\hline Presentation & $\begin{array}{l}\text { First presentation: } 109 / 153(71.2 \%) \\
\text { Recurrence: } 39 / 153(25.5 \%) \\
\text { Missing data: } 5 / 153(3.3 \%)\end{array}$ \\
\hline $\begin{array}{l}\text { Nature of the } \\
\text { lesion }\end{array}$ & $\begin{array}{l}\text { Benign: } 98 / 153(64.1 \%) \\
\text { Malignant: } 55 / 153(35.9 \%)\end{array}$ \\
\hline $\begin{array}{l}\text { Involvement } \\
\text { of the PPS }\end{array}$ & $\begin{array}{l}\text { Primary: } 140 / 153(91.5 \%) \\
\text { Secondary: } 13 / 153(8.5 \%)\end{array}$ \\
\hline $\begin{array}{l}\text { Origin of the } \\
\text { PPS mass }\end{array}$ & $\begin{array}{l}\text { Primary involvement } \\
\text { Salivary: } 76 / 140(54.3 \%) \\
\text { Neurogenic: } 17 / 140(12.1 \%) \\
\text { Vascular: } 16 / 140(11.4 \%) \\
\text { Mesenchymal PPS tissue: } 13 / 140(9.3 \%) \\
\text { Retropharyngeal node(s): } 13 / 140(9.3 \%) \\
\qquad \quad \text { Lymphoproliferative disease: } 1 / 140(0.7 \%) \\
\text { - Nodal metastasis: } 12 / 140(8.6 \%) \\
\circ \quad \text { Nasopharynx: } 5 / 140(3.6 \%) \\
\circ \quad \text { Thyroid gland: } 4 / 140(2.9 \%) \\
\circ \quad \text { Sinonasal tract: } 2 / 140(1.4 \%) \\
\circ \quad \text { Oropharynx: } 1 / 140(0.7 \%) \\
\text { Congenital: } 5 / 140(2.1 \%) \\
\text { Secondary involvement } \\
\text { Oropharynx: } 6 / 13(46.2 \%) \\
\text { Nasopharynx: } 5 / 13(38.5 \%) \\
\text { Orbit: } 1 / 13(7.7 \%) \\
\text { Oral tongue: } 1 / 13(7.7 \%)\end{array}$ \\
\hline
\end{tabular}

the calculation). Therefore, in 12 cases the algorithm failed to predict the approach actually employed (Figure 5; Supplementary Table 4).
(22.9\%) cases, ranging from $8.3 \%$ for schwannomas to $15.4 \%$ for paragangliomas, $25.0 \%$ for PAs, and $32.7 \%$ for PPS malignancies. Radiation therapy was indicated in all recurrent multinodular PAs and all malignancies. Only $30.0 \%$ of patients who had undergone surgery for recurrent multinodular PA accepted to receive adjuvant radiation (45-60 Gy). In patients with PPS malignancies, adjuvant radiotherapy was delivered in only $32.7 \%$ of cases due to several reasons (e.g. contraindication to re-irradiation, postoperative complications, patient's refusal).

In patients affected by primary PPS PA, 10-year LRC was $91.7 \%$, which decreased to $66.7 \%$ in those with recurrent tumors. Both for primary and recurrent PAs, margin involvement did not affect the likelihood of recurrence. Although not reaching statistical significance, 5-year LRC decreased from $100.0 \%$ to $50.0 \%$ in patients with recurrent multinodular PA who did not undergo adjuvant radiation. Intraoperative capsular rupture was reported in $4(10.0 \%)$ cases of primary PAs (multifocal in 2 cases, unifocal in 1 case, unifocal rupture through microdebrider cavitation in a PA that was erroneously diagnosed as a schwannoma at preoperative imaging). Interestingly, in all these 4 cases a local recurrence was identified within $17-42$ months (versus no case of recurrence within 5 years from intact-capsule surgery, $\mathrm{p}=0.002$ ) (Figure 6).

Ten-year LRC was $100.0 \%$ for both paraganglioma and schwannoma.

LRC of malignancies involving the PPS at 3, 5, and 10 years after treatment completion was $62.1 \%, 47.2 \%$, and $42.0 \%$, respectively. This outcome varied substantially when considering margin status: in cancers with involved margins, 3-, 5-, and 10-year LRC was $19.6 \%, 0.0 \%$, and $0.0 \%$, while the same estimates were $78.1 \%, 57.7 \%$, and $57.7 \%$, respectively, when margins were clear $(\mathrm{p}=0.0003)$ (Figure 6). A closeto-significance association between cancer origin and LRC was also observed ( $\mathrm{p}=0.092$ ) (Supplementary Table 5).

Margin status, adjuvant treatment, and disease control

Overall, microscopic margin involvement was observed in 35 
Table 2

Histological diagnosis of tumors included in the study. NOS, not otherwise specified.

\begin{tabular}{|c|c|}
\hline \multicolumn{2}{|c|}{ Tumors with primary involvement of the parapharyngeal space $(140 / 153,91.5 \%)$} \\
\hline Histology & 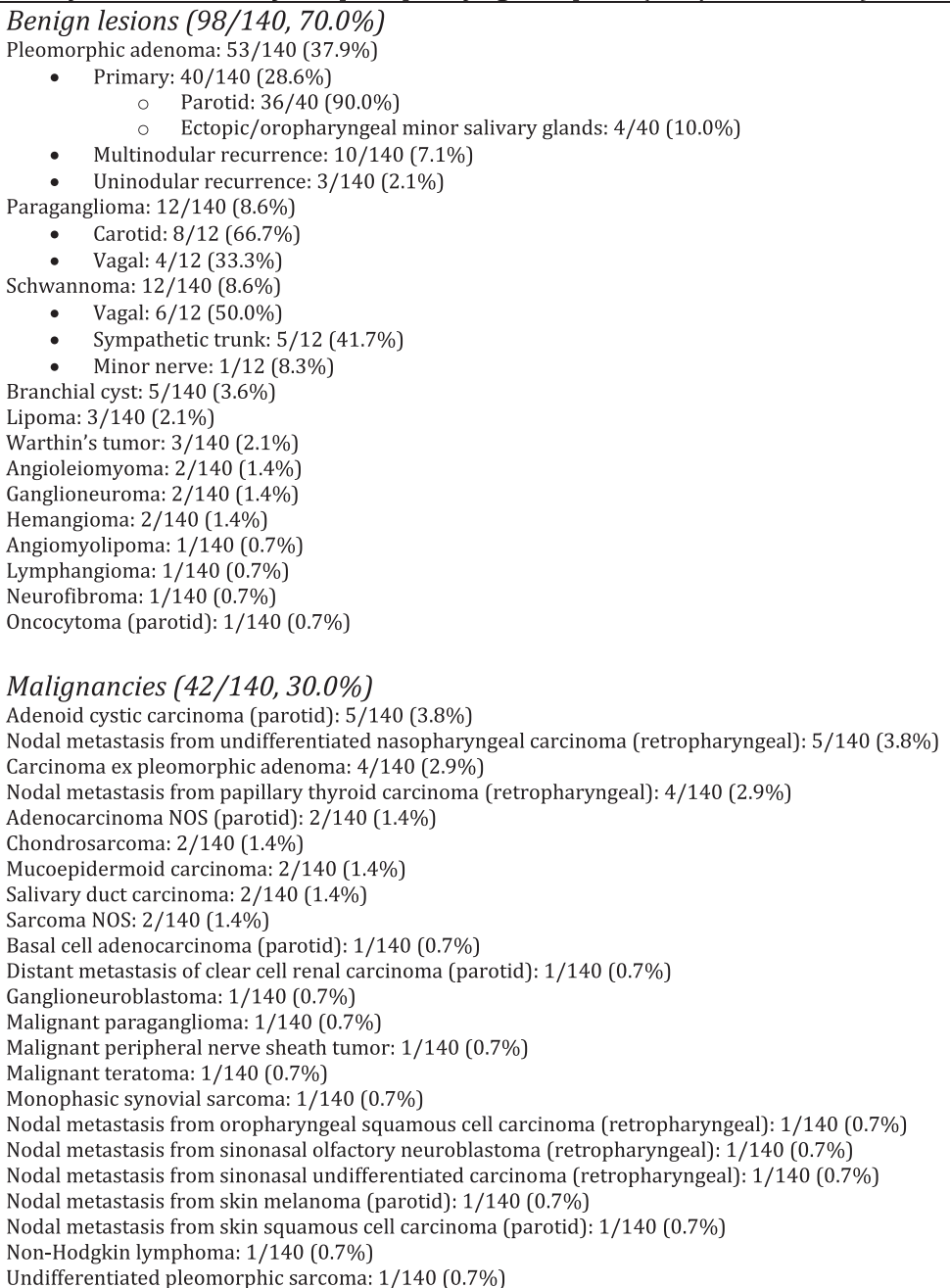 \\
\hline \multicolumn{2}{|c|}{$\begin{array}{l}\text { Tumors with secondary involvement of the parapharyngeal space from adjacent areas } \\
(13 / 153,8.5 \%)\end{array}$} \\
\hline Histology & $\begin{array}{l}\text { Squamous cell carcinoma: } 6 / 13(46.2 \%) \\
\text { Oropharynx: } 4 / 13(30.8 \%) \\
\text { - Lacrimal gland (adenosquamous): } 1 / 13(7.7 \%) \\
\text { Odenoid cystic carcinoma: } 1 / 13(7.7 \%) \\
\text { - Nasopharynx: } 2 / 13(15.4 \%) \\
\text { Oropharynx: } 1 / 13(7.7 \%) \\
\text { Undifferentiated nasopharyngeal carcinoma (nasopharynx): } 2 / 13(15.4 \%) \\
\text { Myoepithelial carcinoma (nasopharynx): } 1 / 13(7.7 \%) \\
\text { Rhabdomyosarcoma, embryonal (oropharynx): } 1 / 13(7.7 \%)\end{array}$ \\
\hline
\end{tabular}

\section{Treatment-related morbidity}

A temporary tracheostomy was performed in 23 (15.0\%) patients. Mean length of hospitalization was 10.9 days (median: 7 days; overall range: 2-45 days; interquartile range: 5-15 days).

Analysis of complications was performed on 150 patients with available data and is summarized in Supplementary Table 6. Comparing patients treated with a multiportal surgery with those undergoing a single-corridor approach, the former group was associated with longer average hospitalization (22.6 days vs. 9.1 days, $\mathrm{p}<0.0001$ ), close-to-significant increase in overall complications (66.7\% vs. $46.0 \%, \mathrm{p}=0.100)$, higher occurrence of oral/oropharyngeal dehiscence/fistula $(21.1 \% v s .1 .5 \%, \mathrm{p}=0.002)$, and more frequent need for temporary tracheostomy $(77.8 \%$ vs. $7.1 \%, \mathrm{p}<0.0001)$.

\section{Discussion}

The present study showed several relevant results arising from the analysis of 153 patients operated on for a lesion involving the PPS over the last 3 decades. The most noticeable finding is that PPS lesions are not infrequently characterized by additional critical features that may further complicate their management [22]. This, along with a remarkable histological heterogeneity, translated into the need to tailor resection according to the profile of the individual tumor. A novel result of the present study is that the surgical approach can be reliably predictable based on the local extension and nature of the tumor, although in a minority of cases intraoperative findings lead to modification of the planned treatment. LRC varied remarkably with histology, and overall morbidity was non-negligible, with $47.3 \%$ of patients experiencing complications. 
Table 3

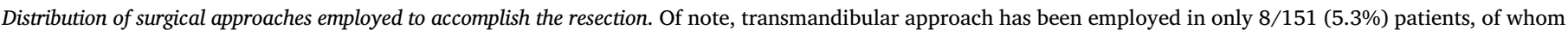


2008, and 1 in 2014), and 3 via a multiportal approach including anterior mandibulotomy in 2017 (2 patients) and 2018 (1 patient).

\begin{tabular}{|c|c|}
\hline Variable & Distribution \\
\hline $\begin{array}{l}\text { Approach } \\
\text { Data missing in } \\
2 \text { cases }\end{array}$ & 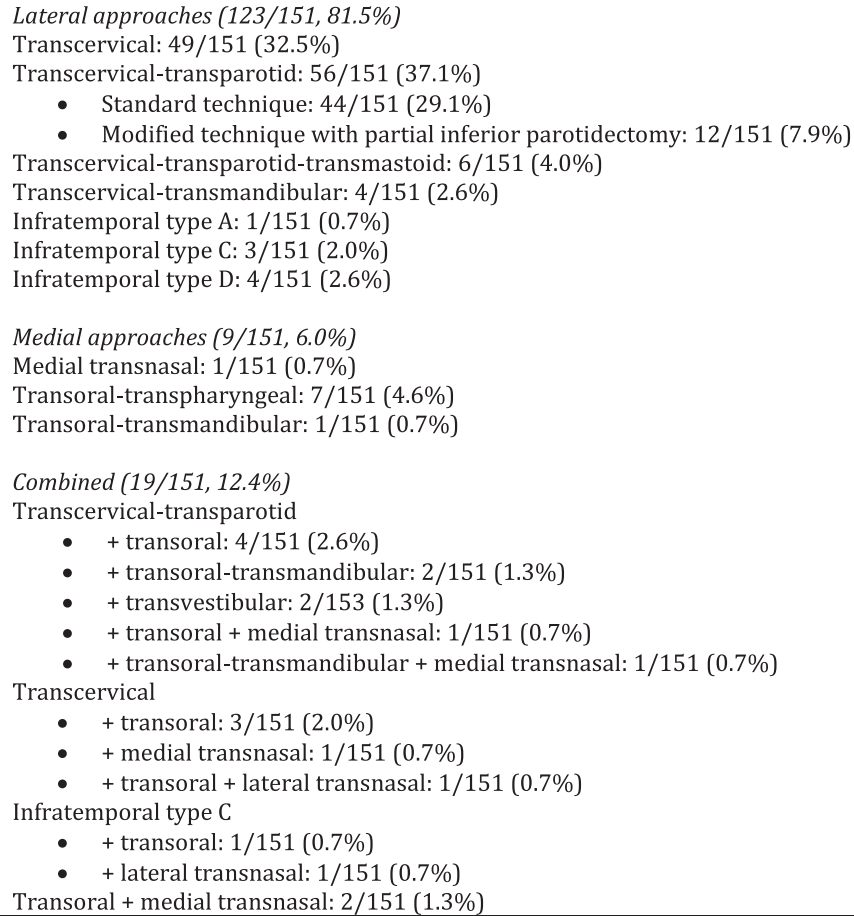 \\
\hline
\end{tabular}

\section{Tumor characteristics}

In line with recent systematic reviews, $[3,4]$ salivary tumors accounted for the vast majority of cases, followed by neurogenic and vascular lesions. This distribution is well mirrored in the frequency of invasion of PPS subunits, with prestyloid subunits, which almost invariably harbor salivary tumors, being more often involved compared to retrostyloid areas, where neurogenic and vascular lesions are usually located. Involvement of areas adjacent to the PPS was most frequently found in pharyngeal walls, infratemporal fossa/masticator space, and lateral skull base. This is the direct consequence of including patients with secondary involvement of the PPS, which was justified by the belief that excision of these tumors should follow the same surgical principles adopted for primary malignancies of the PPS [23-25]. Despite the aforementioned overlap in terms of surgical technique, it is worth highlighting that cancers extending into the PPS from contiguous areas are usually challenging cases of recurrent nasopharyngeal or oropharyngeal tumors that should be thoroughly assessed from a multidisciplinary, oncologic standpoint prior to surgery.

\section{Clinical presentation and work-up}

Clinical presentation aligns with rates of symptoms reported in large scale studies $[3,4]$. Impairment of facial/neck sensitivity was found to significantly predict the malignant nature of the lesion. Diagnostic work-up was centered on cross-sectional imaging, mostly consisting of MRI, which was implemented with cytologic or histologic diagnosis in more than half of cases. Of note, work-up including imaging and FNAC failed to determine the origin and/or nature of the lesion in $22.7 \%$ of cases. This data should alert surgeons about the possibility that diagnosis can substantially change during or following surgery. Matsuki et al. found a higher value of accuracy of FNAC in assessing the benign versus malignant nature of PPS tumors (95.2\%), but the prevalence of malignancies, which were also more frequently misdiagnosed in their study, was remarkably lower compared to our series (10.8\% vs. 35.9\%) [26]. Core-needle biopsy of PPS lesions provided an accuracy of 87-96\%, [27-31] consistent with our findings (90\%).

\section{Resection strategy for benign tumors}

Most PPS tumors in the present series were removed by carrying the dissection between the tumor capsule and surrounding tissues [32]. Moreover, PAs of the deep portion of the parotid were managed following the principle of extracapsular dissection, $[19,20]$ thus leaving a thin cuff of normal salivary tissue attached to the surgical specimen. This strategy conferred a high rate of LRC in the long term, with all patients affected by schwannomas or paragangliomas and $91.7 \%$ of those treated for primary PA being disease-free at 10 years, which is in line with previously published reports [33-35]. Enucleation/extracapsular dissection did not provide a layer of normal tissue all around the entire tumor surface, and consequently led to a high rate of involved margins, which ranged from $8.3 \%$ in schwannomas to $25.0 \%$ in PAs. Moreover, margins were unavoidably involved when the tumor abutted onto a cranial nerve or a major vessel whose sacrifice would have not been considered acceptable. Of note, margin involvement did not decrease LRC of main PPS benign tumors [36]. On the other hand, intraoperative capsular rupture dramatically affected LRC of primary PAs, with all 4 cases with capsular violation recurring within 5 years. These data should prompt surgeons to cautiously select the approach towards PPS-involving PAs, as the consequences of capsular rupture due to inadequate exposure could overweight the additional morbidity of extended/multiportal approaches. Recurrence of PAs involving the PPS has been reported to occur in $0.0 \%-10.3 \%$ of cases $[19,32,33,36,37]$. Capsular rupture is historically thought to increase the risk of recurrence of PA (relative risk: 2-3) [38,39]. Transoral robotic surgery (TORS), along with transoral non-robotic [40] and robotic-assisted transcervical-retroauricular approaches, [41] is emerging as a promising technique to resect PPS tumors [6,41-47]. The main advantage 


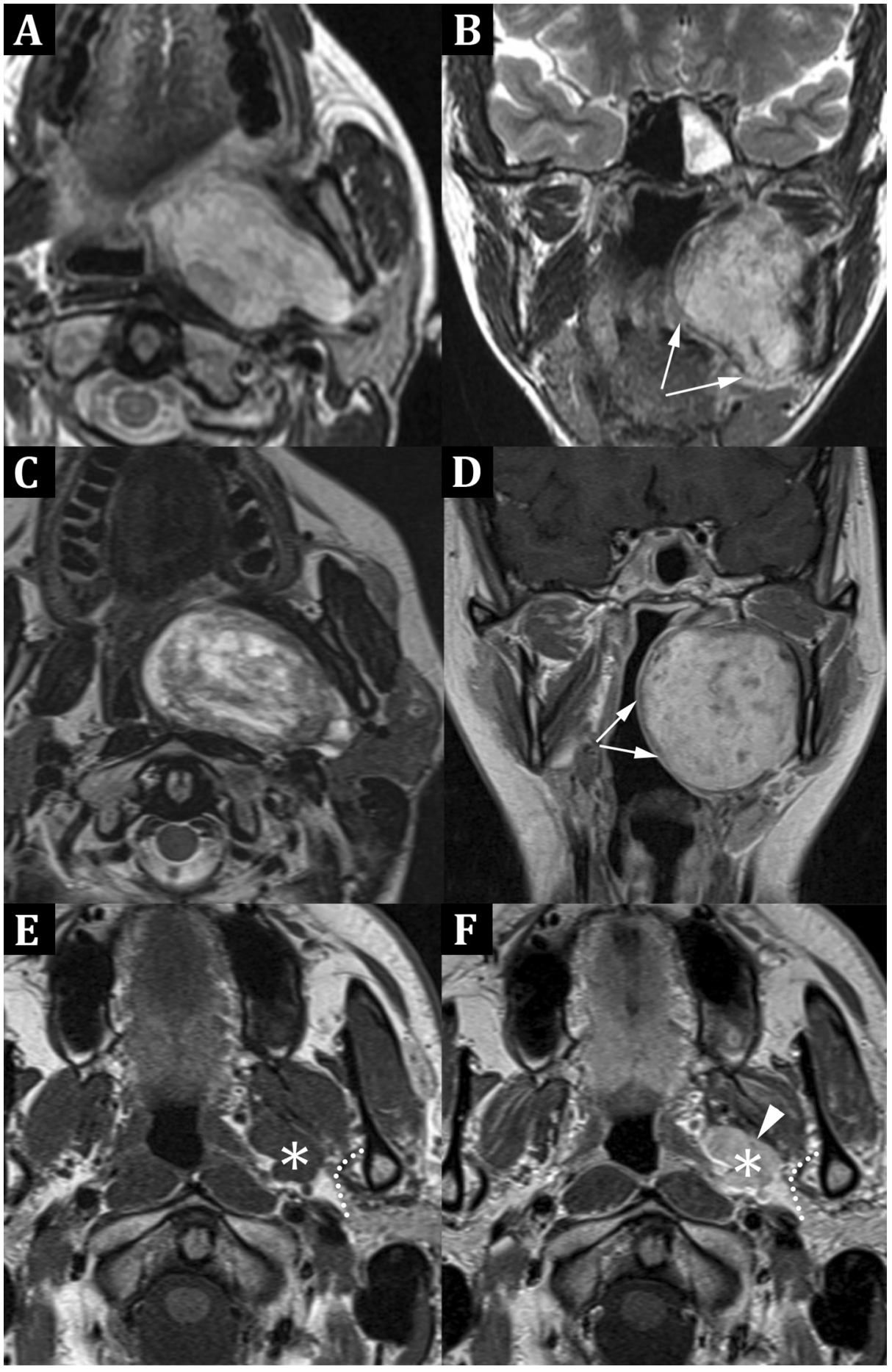

Figure 5. Panel summarizing cases of mismatching between the expected approach and approach actually employed. In A-B and C-D two similar pleomorphic adenomas occupy the parapharyngeal space and are in contact with the deep part of the parotid gland. Both lesions compress the medial pterygoid muscle and the lateral naso- and oropharyngeal wall. Although on coronal plane $(\mathbf{B}, \mathbf{D})$ the constrictor muscle (arrows) is thinned but regular in D, as opposed to the irregular contour shown in $\mathbf{B}$, accurate preoperative prediction of cleavability of the lesion from the muscle is challenging. The case in A-B required a transcervical-transoral-transpharyngeal approach as the tumor was intimately adherent to the lateral oropharyngeal wall, whereas the case in C-D was managed through a transcervical approach, as continuity with respect to the deep part of the parotid gland was intraoperatively excluded. In E-F, uninodular recurrent pleomorphic adenoma (asterisk) is displayed in the parapharyngeal space, separated from the deep part of the parotid gland (dotted line), in contact with the medial pterygoid muscle, with regular and sharp interface (arrowhead). Despite well-defined margins, scar tissue surrounding the lesion was intraoperatively found to create several adhesions towards the adjacent tissues. Therefore, a transcervical approach did not offer adequate exposure and total parotidectomy was required. attributed to TORS is the potential reduction of intraoperative blood loss [41] and complications [42] compared to transcervical approaches, with special reference to facial nerve deficit and first-bite syndrome $[3,4]$. A recent systematic review including 113 patients operated on through TORS for parapharyngeal PA demonstrated a rate of capsular rupture of $14.5 \%$, which compares well to our result (10.0\%) [42].

Multinodular, recurrent PAs of the PPS were treated with compartmental resection, while uninodular recurrences were resected through extracapsular dissection. Five-year LRC was overall $66.7 \%$. Although not reaching statistical significance, adjuvant radiation therapy increased LRC to $100.0 \%$ at 5 years. Adjuvant RT for recurrent PA of the parotid gland (including those involving the PPS) increases LRC and should be indicated on a case-by-case basis [39,48-50].
Kanatas et al. recently published a systematic review of the literature on the management of recurrent PA of the parotid, concluding that adjuvant RT should be given in case of myxoid subtype, large nodules ( $>2 \mathrm{~cm}$ ), tumor satellites, incomplete capsule, and/or positive margins at revision surgery, which includes virtually all cases of recurrent PA of the PPS [51].

Resection strategy for malignant disease

Malignant tumors were clustered in two categories requiring a different degree of healthy margin depending on tumor aggressiveness (i.e. wide margin resection $v s$. compartmental resection). This strategy led to a 5 -year LRC of $47.2 \%$, which noticeably varied from $0.0 \%$ to $57.7 \%$ 
Pleomorphic adenoma

Locoregional control



Locoregional control

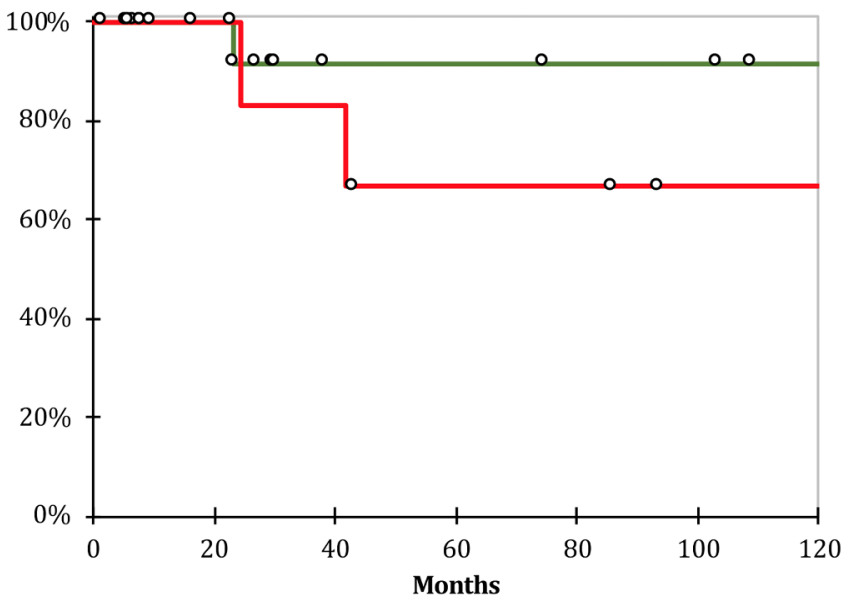

- Primary PA — Recurrent PA
Malignancies of the PPS

Locoregional control

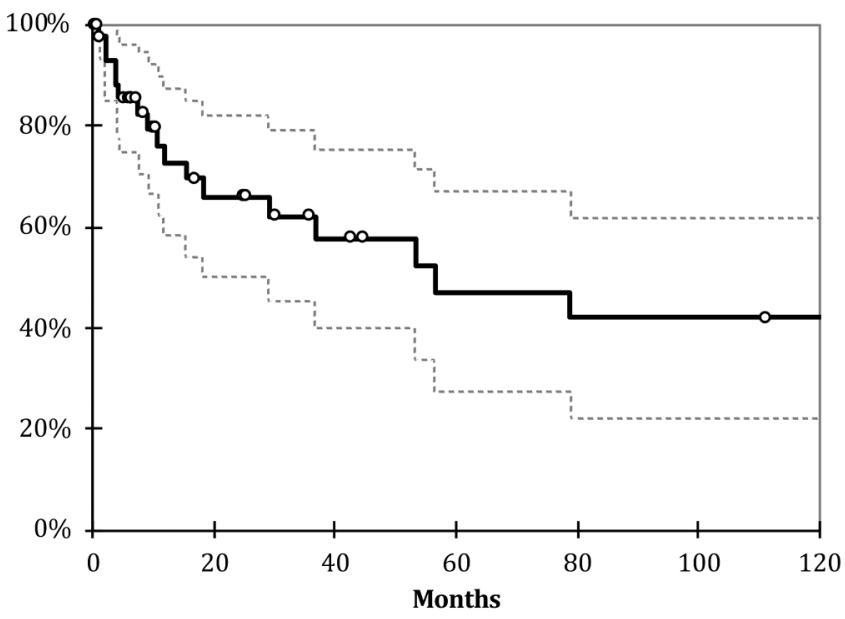

Locoregional control



$-\mathrm{R} 0-\mathrm{R} 1$




involved margins.

when margins were positive or negative, respectively. Therefore, in contrast with what mentioned previously for benign PPS tumors, margin status is of utmost importance in the management of PPS malignancies, and this concept should essentially drive selection of the approach. As expected, cancer origin had a close-to-significant impact on prognosis, thus suggesting that outcomes of malignancies secondarily involving or metastasizing into PPS depend on the behavior of the primary tumor (Supplementary Table 5). According to a systematic review with cumulative analysis of 220 PPS malignancies, 5-year progression-free survival after treatment is $61 \%$ [3]. Van Hees et al. reported an overall survival rate of $44.4 \%$ in patients treated for a PPS malignancy [52].

\section{Selection of approach}

Selection of the approach was intimately related to the volume and extension of tissue to be resected and putative nature of the disease. These two factors being established, the least invasive approach that provided sufficient exposure was selected. Our analysis confirmed that anatomical principles summarized in Figure 1 reliably predicted which approach was indicated for a given volume to resect in $91.2 \%$ of patients. Despite the inherent limitations of a retrospective analysis, this can be considered as a clinical validation of the checklist-algorithm developed according to objective preclinical data obtained from our previous anatomical study [10].

In agreement with large scale data, $[3,4]$ transcervical and transcervical-transparotid approaches are confirmed to be the workhorse of PPS surgery [53,54]. In 12 cases, only partial resection of the parotid gland located caudally to the common trunk, cervicofacial trunk, and mandible-marginal branch was performed (Supplementary Figure 2). In line with the concept of approach modularity, we found this strategy to be a logical stepwise extension from a transcervical to transcervicaltransparotid approach, with the advantage of avoiding morbidity to the temporofacial trunk. This modular approach would also ensure that lesions with an unclear origin (deep lobe $v s$. true PPS) are properly addressed and a possible critical relationship with the facial nerve is identified. In fact, whenever it is not clear if the lesion originates from the parotid deep lobe or is a true PPS tumor, surgery starting with a transcervical approach and possibly extending in a modular fashion is advisable over upfront parotidectomy, which might eventually result to be unneeded for lesions that are easily cleavable off the gland (Supplementary Table 4). Lateral routes through the mandible, mastoid, 
and lateral skull base were employed in selected cases. The possibility to safely resect a PPS tumor through a purely medial access was rare in the present series, with only 9 patients being operated through a medial approach. A mandibulotomy was required in a very restricted number of cases ( 8 patients). This data reflects that several alternatives to anterior mandibulotomy are now available [55]. In addition to its aesthetical and functional consequences, anterior mandibulotomy increases the risk of osteoradionecrosis in patients who will need postoperative radiotherapy [56].

Combination of more than one surgical route was indicated in 19 patients (Supplementary Figure 3). A new classification of combined approaches, able to group a large number of potential combinations under 3 simple categories, was introduced. The decision of combining multiple routes most frequently arose from the need to "horizontally" control the disease on both its posterolateral and anteromedial aspects (i.e. Type 1 combination). Less often, the vertical extension of the tumor mandated combining transnasal and transoral pathways (i.e. Types 2 and 3 combinations) [57]. Combined approaches were associated with increased morbidity compared to single-corridor approaches. This could be attributed not only to an increased surgical trauma, but also to a higher rate of malignant, recurrent, and secondary PPS-involving tumors.

\section{Limitations of the study}

The present study has three main limitations: 1) the quality of data is limited by the retrospective nature of the study over a 33-year timeframe; 2) histologic heterogeneity of PPS tumors mandated simplification of the statistical analysis, which was limited to the most frequent benign tumors and to the cumulative group of malignancies; 3 ) although we do not report personal experience, TORS certainly has the potential to integrate or even substitute classic approaches to the PPS in well-selected cases.

\section{Conclusions}

The present study provided a modern insight on surgery for PPS tumors, based on a large series of patients over 33 years. PPS tumors are variable in histology, and diagnostic work-up is centered on cross-sectional imaging possibly integrated with FNAC or thru-cut biopsy [58]. Primary benign tumors can be resected through enucleation/extracapsular dissection, with special attention to capsular integrity in lesions suspicious for PAs. Malignancies of the PPS should be resected with clear margins. The surgical approach should be selected based on the volume of tissue to be resected, which requires inferring the nature of the lesion and mapping its extension through preoperative workup. Most tumors can be resected through a transcervical/transcervicaltransparotid approach. Multiportal approaches are indicated for complex resections in which planes of dissection cannot be adequately delineated through a single corridor.

\section{Appendix A. Supplementary data}

Supplementary data to this article can be found online at https:// doi.org/10.1016/j.oraloncology.2020.104872.

\section{References}

[1] Stambuk HE, Patel SG. Imaging of the Parapharyngeal Space. Otolaryngol Clin North Am. 2008;41(1):77-101. https://doi.org/10.1016/j.otc.2007.10.012.

[2] Bejjani GK, Sullivan B, Salas-Lopez E, et al. Surgical Anatomy of the Infratemporal Fossa: The Styloid Diaphragm Revisited. Neurosurgery. 1998;43(4):842-52. https://doi.org/10.1097/00006123-199810000-00072.

[3] Kuet M-L, Kasbekar AV, Masterson L, Jani P. Management of tumors arising from the parapharyngeal space: A systematic review of 1,293 cases reported over 25 years. Laryngoscope. 2015;125(6):1372-81. https://doi.org/10.1002/lary.25077.

[4] Riffat F, Dwivedi RC, Palme C, Fish B, Jani P. A systematic review of 1143 parapharyngeal space tumors reported over 20 years. Oral Oncol. 2014;50(5):421-30. https://doi.org/10.1016/j.oraloncology.2014.02.007.

[5] Paderno A, Piazza C, Nicolai P. Recent advances in surgical management of parapharyngeal space tumors. Curr Opin Otolaryngol Head Neck Surg. 2015;23(2):83-90. https://doi.org/10.1097/MOO.0000000000000134.

[6] Boyce BJ, Curry JM, Luginbuhl A, Cognetti DM. Transoral robotic approach to parapharyngeal space tumors: Case series and technical limitations. Laryngoscope. 2016;126(8):1776-82. https://doi.org/10.1002/lary.25929.

[7] Chu F, Tagliabue M, Giugliano G, Calabrese L, Preda L, Ansarin M. From transmandibular to transoral robotic approach for parapharyngeal space tumors. Am J Otolaryngol - Head Neck Med Surg. 2017;38(4):375-9. https://doi.org/10.1016/j. amjoto.2017.03.004.

[8] Dallan I, Fiacchini G, Turri-Zanoni M, et al. Endoscopic-assisted transoral-transpharyngeal approach to parapharyngeal space and infratemporal fossa: focus on feasibility and lessons learned. Eur Arch Oto-Rhino-Laryngology. 2016;273(11):3965-72. https://doi.org/10.1007/s00405-016-4074-6.

[9] Wasano K, Yamamoto S, Tomisato S, Kawasaki T, Ogawa K. Modified endoscopic transnasal-transmaxillary-transpterygoid approach to parapharyngeal space tumor resection. Head Neck. 2016;38(6):933-8. https://doi.org/10.1002/hed.24399.

[10] Ferrari M, Schreiber A, Mattavelli D, et al. Surgical anatomy of the parapharyngeal space: A multiperspective, quantification-based study. Head Neck. 2018. https:// doi.org/10.1002/hed.25378.

[11] Iwanaga J, Watanabe K, Anand MK, Tubbs RS. Air dissection of the spaces of the head and neck: A new teaching and dissection method. Clin Anat. 2020;33(2):207-13. https://doi.org/10.1002/ca.23454.

[12] Ozlugedik S, Acar HI, Apaydin N, et al. Retropharyngeal space and lymph nodes: An anatomical guide for surgical dissection. Acta Otolaryngol. 2005;125(10):1111-5. https://doi.org/10.1080/00016480510035421.

[13] Gavid M, Dumollard JM, Habougit C, et al. Anatomical and histological study of the deep neck fasciae: does the alar fascia exist? Surg Radiol Anat. 2018;40(8):917-22. https://doi.org/10.1007/s00276-018-1977-5.

[14] Clinical Lang J. Anatomy of the Masticatory Apparatus and Peripharyngeal Spaces. G. Thieme Verlag; 1995.

[15] Lang J. Skull Base and Related Structures: Atlas of Clinical Anatomy. Schattauer; 2001. http://books.google.com/books?hl = en\&lr $=$ \&id $=$ pkY-4NJrC0wC\&pgis $=1$. Accessed June 6, 2020.

[16] Prasad SC, Piccirillo E, Chovanec M, La Melia C, De Donato G, Sanna M. Lateral skull base approaches in the management of benign parapharyngeal space tumors Auris Nasus Larynx 2015;42(3):189-98. https://doi.org/10.1016/j.anl.2014.09. 002 .

[17] El-Naggar AK, Chan JKC, Rubin Grandis J, Takata T, Slootweg PJ, International Agency for Research on Cancer. WHO Classification of Head and Neck Tumours.

[18] Nicolai P, Paderno A, Farina D, Piazza C. Microdebrider cavitation and transcervical removal of parapharyngeal schwannomas approaching the skull base. Eur Arch Otorhinolaryngol. 2014;271(12):3305-11. https://doi.org/10.1007/s00405-0142953-2.

[19] Mantsopoulos K, Müller S, Agaimy A, et al. Extracapsular dissection in the parapharyngeal space: benefits and potential pitfalls. Br J Oral Maxillofac Surg. 2017;55(7):709-13. https://doi.org/10.1016/j.bjoms.2017.05.013.

[20] McMullen CP, Smith RV, Ow TJ, Tassler A, Schiff BA. Minimal Margin Extracapsular Dissection: A Viable Alternative Technique for Benign Parotid Lesions? Ann Otol Rhinol Laryngol. 2016;125(11):912-7. https://doi.org/10.1177/ 0003489416661344.

[21] Dindo D, Demartines N, Clavien PA. Classification of surgical complications: A new proposal with evaluation in a cohort of 6336 patients and results of a survey. Ann Surg. 2004;240(2):205-13. https://doi.org/10.1097/01.sla.0000133083.54934.ae.

[22] Cohen SM, Burkey BB, Netterville JL. Surgical management of parapharyngeal space masses. Head Neck. 2005;27(8):669-75. https://doi.org/10.1002/hed. 20199.

[23] Battaglia P, Turri-Zanoni M, Dallan I, et al. Endoscopic Endonasal Transpterygoid Transmaxillary Approach to the Infratemporal and Upper Parapharyngeal Tumors. Otolaryngol Neck Surg. 2014;150(4):696-702. https://doi.org/10.1177/ 0194599813520290.

[24] Rubin F, Laccourreye O, Weinstein GS, Holsinger FC. Transoral lateral oropharyngectomy. Eur Ann Otorhinolaryngol Head Neck Dis. 2017;134(6):419-22. https://doi.org/10.1016/j.anorl.2017.06.002.

[25] De Virgilio A, Kim SH, Magnuson JS, et al. Anatomical-based classification for transoral lateral oropharyngectomy. Oral Oncol. 2019;99:104450. https://doi.org/ 10.1016/j.oraloncology.2019.104450.

[26] Matsuki T, Miura K, Tada Y, et al. Classification of tumors by imaging diagnosis and preoperative fine-needle aspiration cytology in 120 patients with tumors in the parapharyngeal space. Head Neck. 2019;41(5):1277-81. https://doi.org/10.1002/ hed.25552.

[27] Wu EH, Chen YL, Wu YM, Huang YT, Wong HF, Ng SH. CT-guided core needle biopsy of deep suprahyoid head and neck lesions. Korean J Radiol. 2013;14(2):299-306. https://doi.org/10.3348/kjr.2013.14.2.299.

[28] Connor SEJ, Chaudhary N. CT-guided percutaneous core biopsy of deep face and skull-base lesions. Clin Radiol. 2008;63(9):986-94. https://doi.org/10.1016/j.crad. 2008.04.013.

[29] Chen R, Cai Q, Liang F, Lin P, Chen L. Oral core-needle biopsy in the diagnosis of malignant parapharyngeal space tumors. Am J Otolaryngol - Head Neck Med Surg. 2019;40(2):233-5. https://doi.org/10.1016/j.amjoto.2018.11.005.

[30] Kim HJ, Kim JS. Ultrasound-guided core needle biopsy in salivary glands: A metaanalysis. Laryngoscope. 2018;128(1):118-25. https://doi.org/10.1002/lary.26764.

[31] Shah KSV, Ethunandan M. Tumour seeding after fine-needle aspiration and core biopsy of the head and neck - A systematic review. Br J Oral Maxillofac Surg. 2016;54(3):260-5. https://doi.org/10.1016/j.bjoms.2016.01.004. 
[32] Yang TL, Hsiao TY, Wang CP, Lou PJ, Ko JY. Extracapsular dissection for minimal resection of benign parapharyngeal tumor. Eur Arch Oto-Rhino-Laryngology. 2012;269(9):2097-102. https://doi.org/10.1007/s00405-011-1855-9.

[33] Horowitz G, Ben-Ari O, Wasserzug O, Weizman N, Yehuda M, Fliss DM. The transcervical approach for parapharyngeal space pleomorphic adenomas: indications and technique. PLoS ONE 2014;9(2):e90210. https://doi.org/10.1371/ journal.pone.0090210.

[34] Zheng X, Guo K, Wang H, et al. Extracranial schwannoma in the carotid space: A retrospective review of 91 cases. Head Neck. 2017;39(1):42-7. https://doi.org/10. 1002/hed.24523.

[35] Moore MG, Netterville JL, Mendenhall WM, Isaacson B, Nussenbaum B. Head and Neck Paragangliomas. In: Otolaryngology - Head and Neck Surgery (United States). Vol 154. SAGE Publications Inc.; 2016:597-605. doi:10.1177/0194599815627667.

[36] Guo Y, Guo C, Zhang L, Yu G. Extracapsular dissection of the parapharyngeal space for a pleomorphic adenoma: A 10-year review. Br J Oral Maxillofac Surg. 2014;52(6):557-62. https://doi.org/10.1016/j.bjoms.2014.02.019.

[37] Mendelsohn AH, Bhuta S, Calcaterra TC, Shih HB, Abemayor E, St John MA. Parapharyngeal space pleomorphic adenoma: a 30-year review. Laryngoscope. 2009;119(11):2170-4. https://doi.org/10.1002/lary.20496.

[38] Colella G, Cannavale R, Chiodini P. Meta-analysis of surgical approaches to the treatment of parotid pleomorphic adenomas and recurrence rates. $\mathrm{J}$ Craniomaxillofac Surg. 2015;43(6):738-45. https://doi.org/10.1016/j.jcms.2015. 03.017.

[39] Witt RL, Eisele DW, Morton RP, Nicolai P, Vander Poorten V, Zbären P. Etiology and management of recurrent parotid pleomorphic adenoma. Laryngoscope. 2015;125(4):888-93. https://doi.org/10.1002/lary.24964.

[40] Liu Y, Yu H-J, Zhen H-T. Transoral and endoscope-assisted transoral approaches to resecting benign tumours of the parapharyngeal space located in the medial portion of the carotid sheaths and extending toward the skull base: our experience. $\mathrm{J}$ Laryngol Otol. 2018;132(8):748-52. https://doi.org/10.1017/ S0022215118001184.

[41] Lim JY, Park YM, Kang MS, et al. Comparison of Surgical Outcomes of Robotic and Conventional Approaches in Patients with Pre- and Poststyloid Parapharyngeal Space Tumors. Ann Surg Oncol. 2020. https://doi.org/10.1245/s10434-02008536-0.

[42] De Virgilio A, Costantino A, Mercante G, Di Maio P, Iocca O, Spriano G. Trans-oral robotic surgery in the management of parapharyngeal space tumors: A systematic review. Oral Oncol. 2020;103:104581. https://doi.org/10.1016/j.oraloncology. 2020.104581.

[43] Maglione MG, Guida A, Pavone E, et al. Transoral robotic surgery of parapharyngeal space tumours: a series of four cases. Int J Oral Maxillofac Surg. 2018;47(8):971-5. https://doi.org/10.1016/j.ijom.2018.01.008.

[44] Mendelsohn AH. Transoral robotic assisted resection of the parapharyngeal space. Head Neck. 2015;37(2):273-80. https://doi.org/10.1002/hed.23724.

[45] Park YM, De Virgilio A, Kim WS, Chung HP, Kim S-H. Parapharyngeal space surgery via a transoral approach using a robotic surgical system: transoral robotic surgery. J Laparoendosc Adv Surg Tech A. 2013;23(3):231-6. https://doi.org/10.1089/lap. 2012.0197.
[46] Arshad H, Durmus K, Ozer E. Transoral robotic resection of selected parapharyngeal space tumors. Eur Arch Oto-Rhino-Laryngology. 2013;270(5):1737-40. https://doi. org/10.1007/s00405-012-2217-y.

[47] O'Malley BW, Quon H, Leonhardt FD, Chalian AA, Weinstein GS. Transoral robotic surgery for parapharyngeal space tumors. ORL J Otorhinolaryngol Relat Spec. 2010;72(6):332-6. https://doi.org/10.1159/000320596.

[48] Chen AM, Garcia J, Bucci MK, Quivey JM, Eisele DW. Recurrent pleomorphic adenoma of the parotid gland: Long-term outcome of patients treated with radiation therapy. Int J Radiat Oncol Biol Phys. 2006;66(4):1031-5. https://doi.org/10. 1016/j.ijrobp.2006.06.036.

[49] Mc Loughlin L, Gillanders SL, Smith S, Young O. The role of adjuvant radiotherapy in management of recurrent pleomorphic adenoma of the parotid gland: a systematic review. Eur Arch Otorhinolaryngol. 2019;276(2):283-95. https://doi.org/ 10.1007/s00405-018-5205-z.

[50] Renehan A, Gleave EN, McGurk M. An analysis of the treatment of 114 patients with recurrent pleomorphic adenomas of the parotid gland. In: American Journal of Surgery. Vol 172. ; 1996:710-714. doi:10.1016/S0002-9610(96)00293-0.

[51] Kanatas A, Ho MWS, Mücke T. Current thinking about the management of recurrent pleomorphic adenoma of the parotid: a structured review. Br J Oral Maxillofac Surg. 2018;56(4):243-8. https://doi.org/10.1016/j.bjoms.2018.01.021.

[52] van Hees T, van Weert S, Witte B, René Leemans C. Tumors of the parapharyngeal space: the VU University Medical Center experience over a 20-year period. Eur Arch Oto-Rhino-Laryngology. 2018;275(4):967-72. https://doi.org/10.1007/s00405018-4891-x.

[53] Basaran B, Polat B, Unsaler S, Ulusan M, Aslan I, Hafiz G. Parapharyngeal space tumours: the efficiency of a transcervical approach without mandibulotomy through review of 44 cases. Acta Otorhinolaryngol Ital. 2014;34(5):310-316 http://www.ncbi.nlm.nih.gov/pubmed/25709146. Accessed March 29, 2020.

[54] Casani AP, Cerchiai N, Dallan I, Seccia V, Sellari Franceschini S. Benign tumours affecting the deep lobe of the parotid gland: how to select the optimal surgical approach. Acta Otorhinolaryngol Ital. 2015;35(2):80-87. http://www.ncbi.nlm.nih. gov/pubmed/26019390. Accessed March 29, 2020.

[55] Presutti L, Molteni G, Malvè L, et al. Parapharyngeal space tumors without mandibulotomy: our experience. Eur Arch Otorhinolaryngol. 2012;269(1):265-73. https://doi.org/10.1007/s00405-011-1594-y.

[56] Raguse JD, Hossamo J, Tinhofer I, et al. Patient and treatment-related risk factors for osteoradionecrosis of the jaw in patients with head and neck cancer. Oral Surg Oral Med Oral Pathol Oral Radiol. 2016;121(3):215-221.e1. https://doi.org/10. 1016/j.0ooo.2015.10.006.

[57] Turri-Zanoni M, Battaglia P, Dallan I, Locatelli D, Castelnuovo P. Multiportal combined transnasal transoral transpharyngeal endoscopic approach for selected skull base cancers. Head Neck. 2016;38(6):E2440-5. https://doi.org/10.1002/hed. 24405.

[58] Muraz E, Delemazure AS, Mourrain-Langlois E, Bourget K, Malard O, Frampas E. Peripharyngeal space tumors: Can magnetic resonance and multidetector-row computed tomography help predict location, malignancy and tumor type? Diagn Interv Imaging. 2016;97(6):617-25. https://doi.org/10.1016/j.diii.2015.09.015. 